\title{
REDUÇÃO DA PERDA METÁLICA NA ACIARIA DA GERDAU USINA DE OURO BRANCO*
}

\author{
Eric Novaes de Almeida ${ }^{1}$ \\ Carlos Vinícius Domingos de Carvalhor ${ }^{2}$ \\ Jorge Adam Cleto Cohn ${ }^{3}$ \\ Rui Coelho de Assis Filho ${ }^{4}$ \\ Tito Hugo Nogueira Coelho 5
}

\section{Resumo}

As perdas geradas nos processos de uma Aciaria contribuem de forma significativa para a perda metálica do processo. Eventualmente, mesmo com uma operação correta, do ponto de vista de características do produto, pode ocorrer comprometimento do ponto de vista econômico, e uma forma de redução direta dos custos e aumento de performance é a redução das perdas geradas no processo. Desta forma, tornou-se importante realizar um estudo para reduzir as perdas metálicas na Aciaria. Foi utilizado a metodologia Seis Sigma, sendo estratificadas as perdas por processo na Aciaria, onde as maiores perdas na rota dos processos de Lingotamentos Contínuos foram: perda no Distribuidor (24,7\%), corte de sequência (17,5\%), retorno de corrida por baixa temperatura do aço na panela (16,3\%); perda por obstrução da válvula da panela $(8,8 \%)$. A perda metálica foi reduzida em $50,8 \%$. Além da redução expressiva das perdas, houve uma grande contribuição em relação à compreensão dos modos de falhas para apropriação correta das perdas, tornando as informações mais seguras e facilitando o tratamento de possíveis falhas no processo.

Palavras-chave: Lingotamentos Contínuos; Perda metálica; Distribuidor; Corte de sequência.

\section{Abstract \\ REDUCTION OF METALLIC LOSS IN GERDAU'S STEELMAKING}

The losses generated in the processes of a Steelmaking plant contribute significantly to the metallic loss of the process. Eventually, even with a correct operation, from the point of view of product characteristics, may be an impairment from an economic point of view, and a way of directly reducing costs and an important way to increase performance is the reduction of losses generated in the process. A study to reduce metal losses in the Steelmaking plant is significant to reduce the total loss of the plant. Using Six Sigma methodology, we stratified the process losses, where the largest of the Continuous Casting were: tundish loss of $24,7 \%$, sequence brake of $17,5 \%$ returning of ladle due to low temperature $16,3 \%$ and ladle nozzle obstruction during continuous casting $8,8 \%$. The metal losses was reduced in $50,8 \%$. In addition to the significant reduction of losses, there was a contribution to the understanding of the modes of failure this information contribute to correct appropriation of losses, with reliable information the treatment of possible failures in the process was more effective. Keywords: Continuous Casting; metallic loss; Tundish; Sequence brake.

Engenheiro Metalurgista, Consultor Técnico de Aciaria, Gerdau, Ouro Branco-MG, Brasil. Engenheiro Metalurgista, Assessor Técnico de Aciaria, Gerdau, Ouro Branco-MG, Brasil. Engenheiro Metalurgista, Consultor Técnico de P\&D, Gerdau, Ouro Branco-MG, Brasil. Engenheiro Metalurgista, Assessor Técnico de Aciaria, Gerdau, Ouro Branco-MG, Brasil. Engenheiro Metalurgista, Assessor Técnico de Aciaria, Gerdau, Ouro Branco-MG, Brasil. 


\section{INTRODUÇÃO}

As perdas geradas nos processos de uma Aciaria definem a perda metálica podendo este indicador variar se comparado a outras empresas. Eventualmente, mesmo uma operação correta, do ponto de vista de características do produto, pode ser comprometida do ponto de vista econômico. As empresas de especialidades em refratário têm estudado as diversas causas da sobra de aço na panela antes e após o fechamento da panela. Por mais que se possuam técnicas para minimização da quantidade de escória na panela como o AMEPA (equipamento de equalização da quantidade de escória passante da panela para o Distribuidor), tem-se ainda uma quantidade de aço remanescente na panela após fechamento, ou esta sobra pode ser elevada quando ocorre obstrução da válvula por clogging aumentando o índice de retorno de corridas [1]. Muitos especialistas classificam como a causa deste aço remanescente na panela após seu fechamento devido ao tipo de fundo refratário da panela, onde fundos horizontais propiciam a formação do vortex (redemoinho) antecipadamente se comparado a fundos inclinados [2]. A figura 1 apresenta um típico fluxo de aço da Panela para o Distribuidor, onde existe um limite de altura tal que não ocorra intensa formação de vortex.

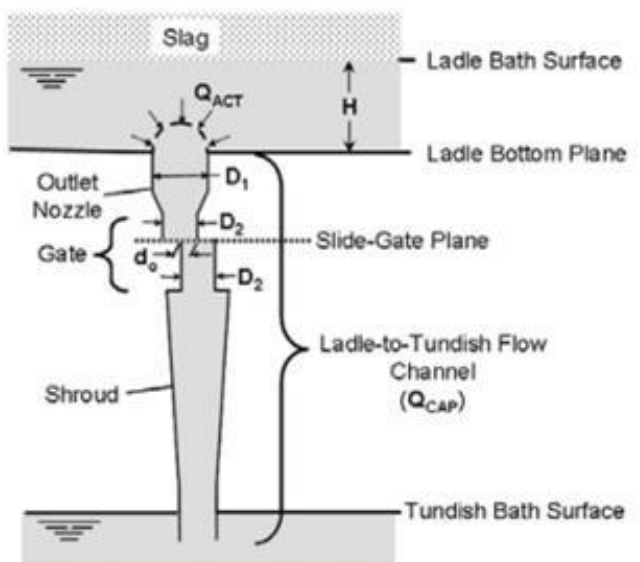

Figura 1- Típico Fluxo de aço líquido da panela transferido para o Distribuidor (Relatório Interno da Gerdau, 2013).

O presente estudo buscou estratificar as perdas no processo da Aciaria da Gerdau usina de Ouro Branco para identificar quais seriam as perdas no processo e trabalhalas separadamente, avaliando as formas de reduzi-las e garantir a redução da perda metálica na Aciaria.

A perda metálica é calculada conforme a equação 1:

Perda metálica $=\frac{\text { Perdas nas baias da Aciaria }[\mathrm{kg}]+\text { perdas nos Lingotamentos }[\mathrm{kg}]}{\text { Peso lingotado total na Aciaria }[\mathrm{t}]}$

Foi estabelecido uma meta desafiadora em função dos objetivos de redução de custo da empresa alinhados ao mapa estratégico, onde a meta de redução foi de $32 \%$, conforme figura 2: 


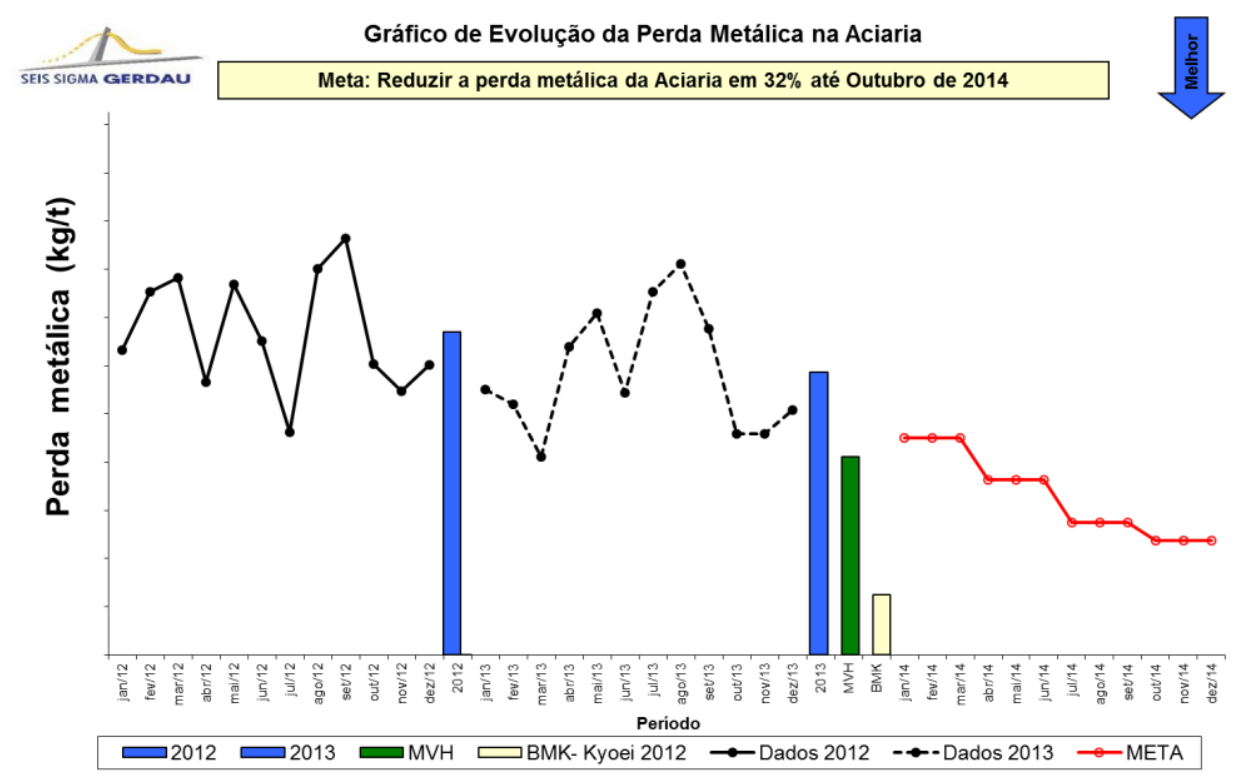

Figura 2- Evolução da Perda Metálica na Aciaria e definição da meta

Associado ao fundo reto da panela de aço, existe outra causa do aço remanescente na panela após final de corrida que é devido ao efeito do diâmetro da válvula gaveta posicionada no fundo da panela, onde em função do diâmetro da válvula e, à medida que a coluna de aço diminui durante o lingotamento, tem-se uma redução drástica da vazão em (t/min), sendo fator importante para retenção do aço na panela.

A figura 3 apresenta o efeito do diâmetro da válvula gaveta na panela de aço do Lingotamento Contínuo de Placas da Gerdau Usina Ouro Branco [2].

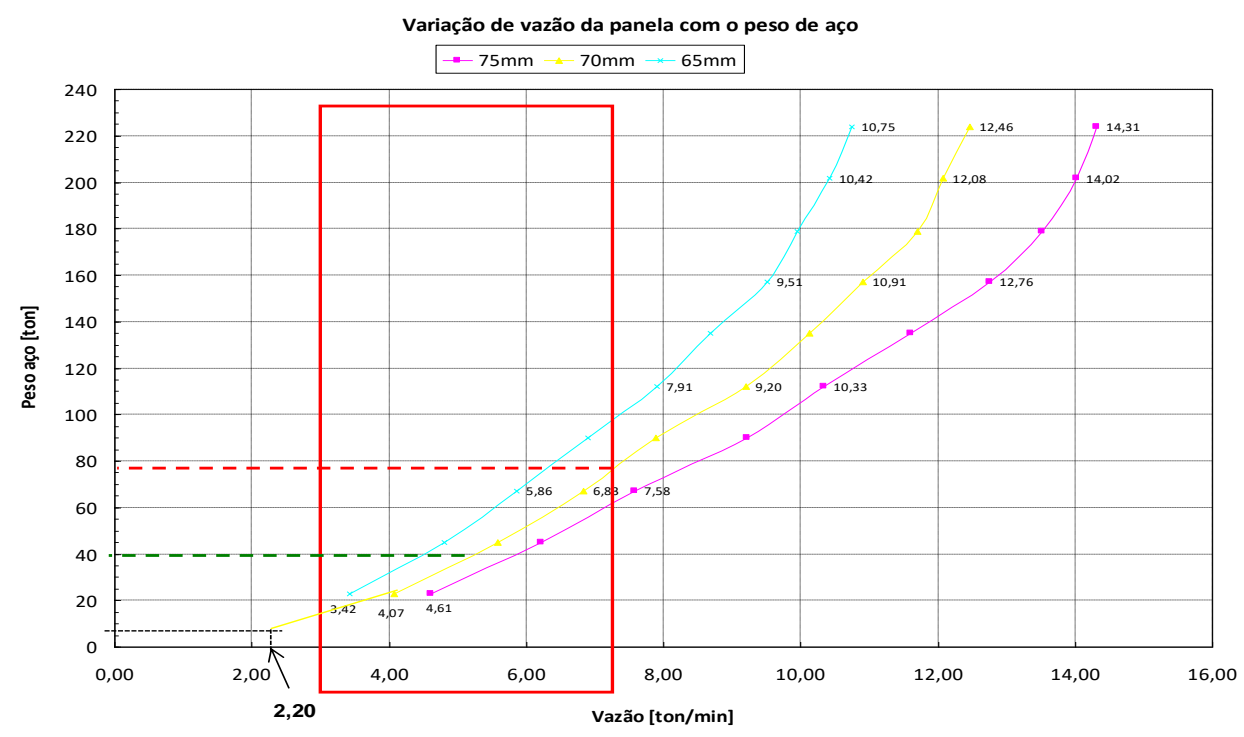

Figura 3- Efeito do diâmetro da válvula gaveta da panela do Lingotamento Contínuo de Placas da Gerdau (Relatório Interno da Gerdau, 2012).

A figura 4 e 5 apresentam dois gráficos de relações teóricas, onde a figura 4 indica à predição de formação de redemoinhos em função da altura de coluna de aço e da vazão (t/min), e a figura 5 indica a relação entre o diâmetro da base da panela que é de aproximadamente 3 metros com a vazão em (t/min), indicando teoricamente a 
quantidade de escória para uma panela de fundo horizontal, que com os parâmetros operacionais dos Lingotamentos o valor seria de 2,2 toneladas [2].

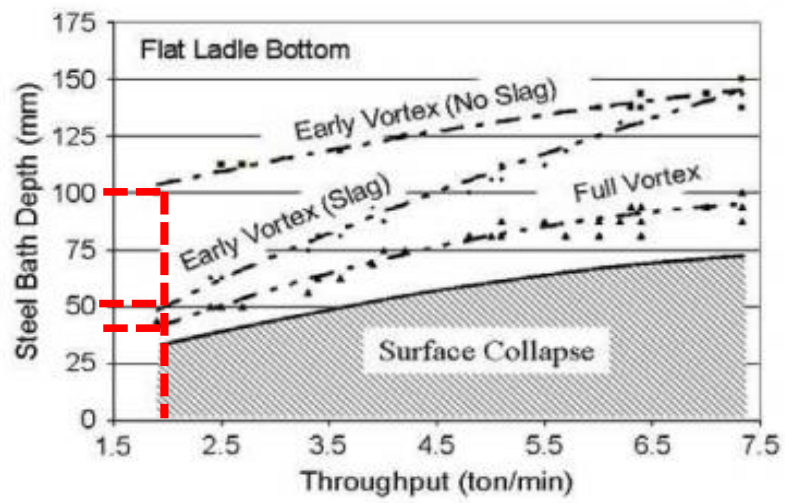

Figura 4- Predição de formação de redemoinhos em função da altura de colina de aço e da vazão (Relatório Interno da Gerdau, 2013).

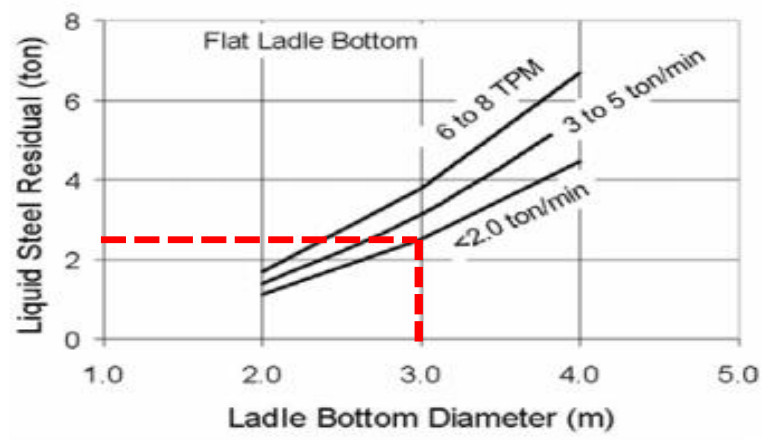

Figura 5- Relação entre o diâmetro da base da panela com a vazão indicando a escória teórica (Relatório Interno da Gerdau, 2013).

\section{MATERIAIS E MÉTODOS}

Para a condução deste projeto, foi utilizada a metodologia seis sigma, onde inicialmente foi realizado um balanço de massa na Aciaria para identificar quais são as fontes das perdas no processo e mapeá-las de forma que pudesse cadastrá-las para compor a árvore de perdas, aumentando assim a confiabilidade da árvore de perdas. Na fase de análise do fenômeno, foram realizadas as estratificações dos dados identificado os problemas críticos, sendo estabelecida a árvore em função da rota do processo de cada Lingotamento Contínuo. Desta forma, todos os problemas críticos foram tratados na fase de análise do processo, utilizando o diagrama de causa e efeito para avaliar as causas mais prováveis do problema crítico. Após identificação dos fatores causais, foram definidas as medidas a serem implementadas e criou-se o plano de ação. Toda a execução foi monitorada para que não ocorresse desvios e, após implantação de todas as ações, foi realizada a verificação dos resultados, onde as pessoas foram treinadas nos novos procedimentos. 


\section{RESULTADOS E DISCUSSÃO}

\subsection{Análise do fenômeno}

$\mathrm{Na}$ análise do fenômeno, foram estratificados os dados e foram priorizados 17 problemas críticos. Na tabela 1 estão apresentadas as prioridades dos problemas críticos.

Tabela 1- Estratificação dos problemas críticos de maior relevância para a perda metálica na aciaria

\begin{tabular}{|c|c|}
\hline Item & Ordem de Prioridade \\
\hline \begin{tabular}{|l|} 
LCP: Perda Distribuidor \\
\end{tabular} & $1 \stackrel{0}{1}$ \\
\hline LCT: Baixa Temperatura & $2 \circ$ \\
\hline LCP: Obstrução Válvula da Panela & $3 \circ$ \\
\hline LCB: Perda Distribuidor & $4 \stackrel{0}{\circ}$ \\
\hline LCB: Corte de Sequência & 50 \\
\hline LCB: Desvio & $6 \stackrel{0}{\circ}$ \\
\hline LCT: Carepa & $7 \stackrel{0}{\circ}$ \\
\hline LCT:Desvio & $8 \stackrel{0}{\circ}$ \\
\hline LCB: Desponte Final & $9 \stackrel{0}{9}$ \\
\hline LCT: Corte de Sequência & $10 \stackrel{\circ}{10}$ \\
\hline LCT: Perda Distribuidor & $11^{\circ} \stackrel{0}{1}$ \\
\hline LCP: Baixa Temperatura & $12 \stackrel{\circ}{2}$ \\
\hline LCP: Corte de Sequência & $13^{\circ}$ \\
\hline LCB: Baixa Temperatura & $14^{\circ} \stackrel{\circ}{1}$ \\
\hline LCT: Aço na Baia Antes & $15^{\circ}$ \\
\hline LCB: Aço na Baia Antes & $16^{\circ} \stackrel{0}{1}$ \\
\hline LCP: Desponte final & $17^{\circ} \stackrel{0}{ }$ \\
\hline
\end{tabular}

\subsection{Análise do processo}

As maiores perdas dos processos na rota dos Lingotamentos Contínuos de Tarugos (LCT), Blocos (LCB) e Placas (LCP) possuem as seguintes participações na perda geral: perda no Distribuidor (24,7\%), perda por corte de sequência (17,5\%), retorno de corrida por baixa temperatura do aço na panela (16,3\%) e perda por obstrução da panela no Lingotamento de Placas (8,8 \%), porém, estas perdas são correlacionáveis, por exemplo, na rota do LCP, as perdas no Distribuidor, corte de sequência são decorrentes das perdas por obstrução na válvula da panela no Lingotamento Contínuo de Placas, pois, na maioria das vezes a máquina encerra sua sequência e por sua vez, gera uma elevada sobra de aço no Distribuidor. Os retornos por baixa temperatura estão correlacionados com o aço na baia antes da panela ir para o lingotamento, pois, problemas de variação de carga na panela, geram necessidade de retirar o aço da panela para tratamento no refino secundário e por sua vez, impactam na temperatura do aço. Desta forma, foram agrupados e priorizadas a análise do processo no problema crítico obstrução da válvula da panela no lingotamento contínuo de Placas e peso de aço na baia antes da panela ir para a torre dos Lingotamentos Contínuos. 


\subsubsection{Problema Crítico: Obstrução da válvula da panela no Lingotamento Contínuo de Placas (LCP)}

$\mathrm{Na}$ análise do processo, foram identificadas as causas potenciais que estava gerando cada problema, onde foi avaliado o problema de obstrução da válvula da panela no LCP (Lingotamento Contínuo de Placas). Realizando a quantificação do relacionamento entre variáveis (potencial causa versus problema focado), foram definidos os seguintes parâmetros de processo a serem avaliados: alto nível de oxigênio fim de sopro; alto volume de escória na panela e escória na panela podendo reagir com a alumina formando aluminato de cálcio de difícil flotação;

Existe uma correlação forte entre o oxigênio fim de sopro, escória na panela (passada durante o vazamento no Convertedor) e adição de alumínio, onde são variáveis que impactam diretamente na qualidade do aço e no retorno de corrida devido a ocorrência de clogging na válvula da panela. As figuras 6 e 7 apresentam respectivamente a correlação entre as três variáveis do processo juntamente com a meta específica para oxigênio fim de sopro $(900$ ppm) e escória na panela $(1000 \mathrm{~kg})$ para reduzir a formação de alumina na válvula da panela e reduzir a incidência do clogging.

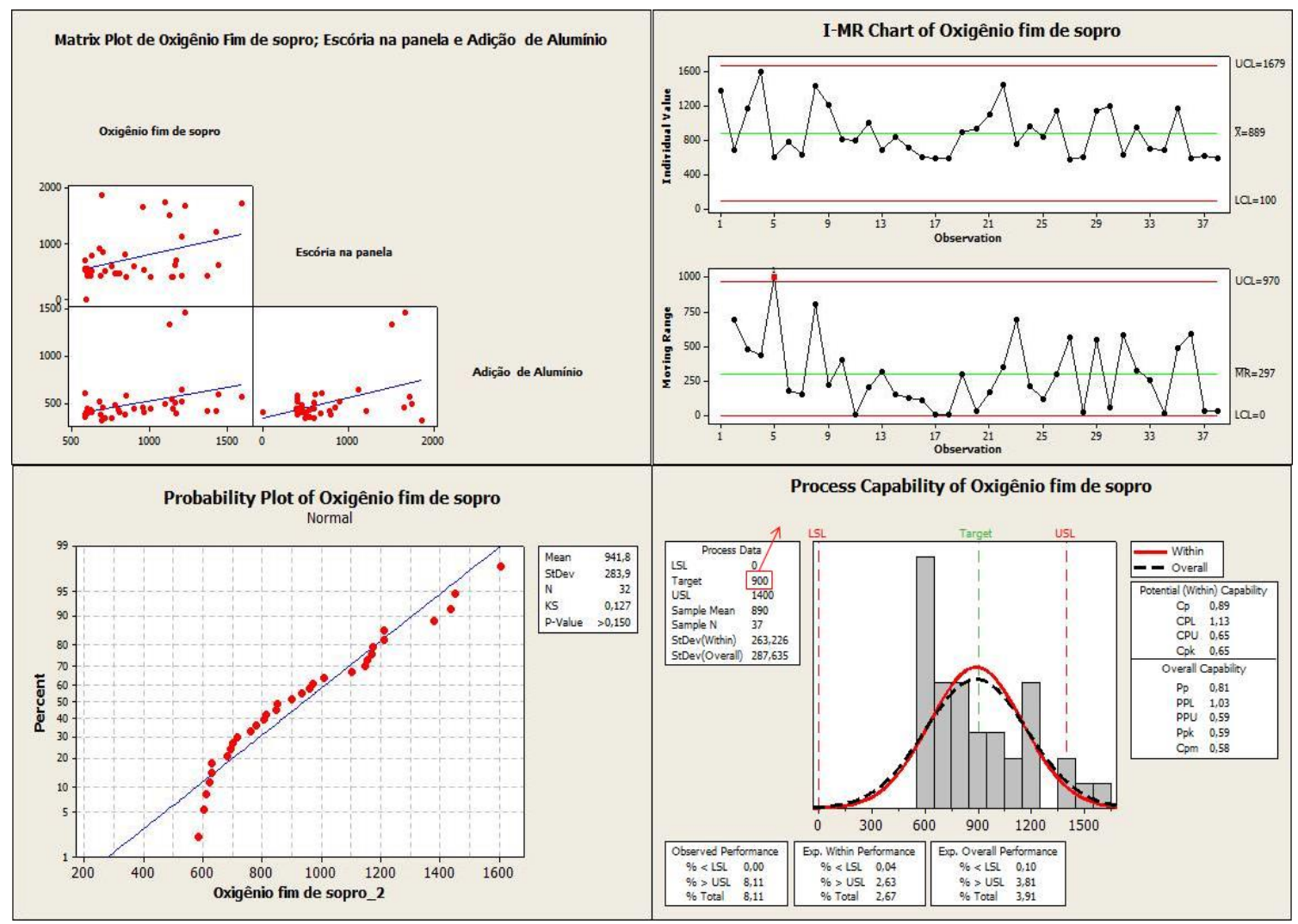

Figura 6- Correlação entre o oxigênio fim de sopro com a escória na panela e a adição de alumínio com a meta específica de redução Oxigênio fim de sopro (900 ppm) 


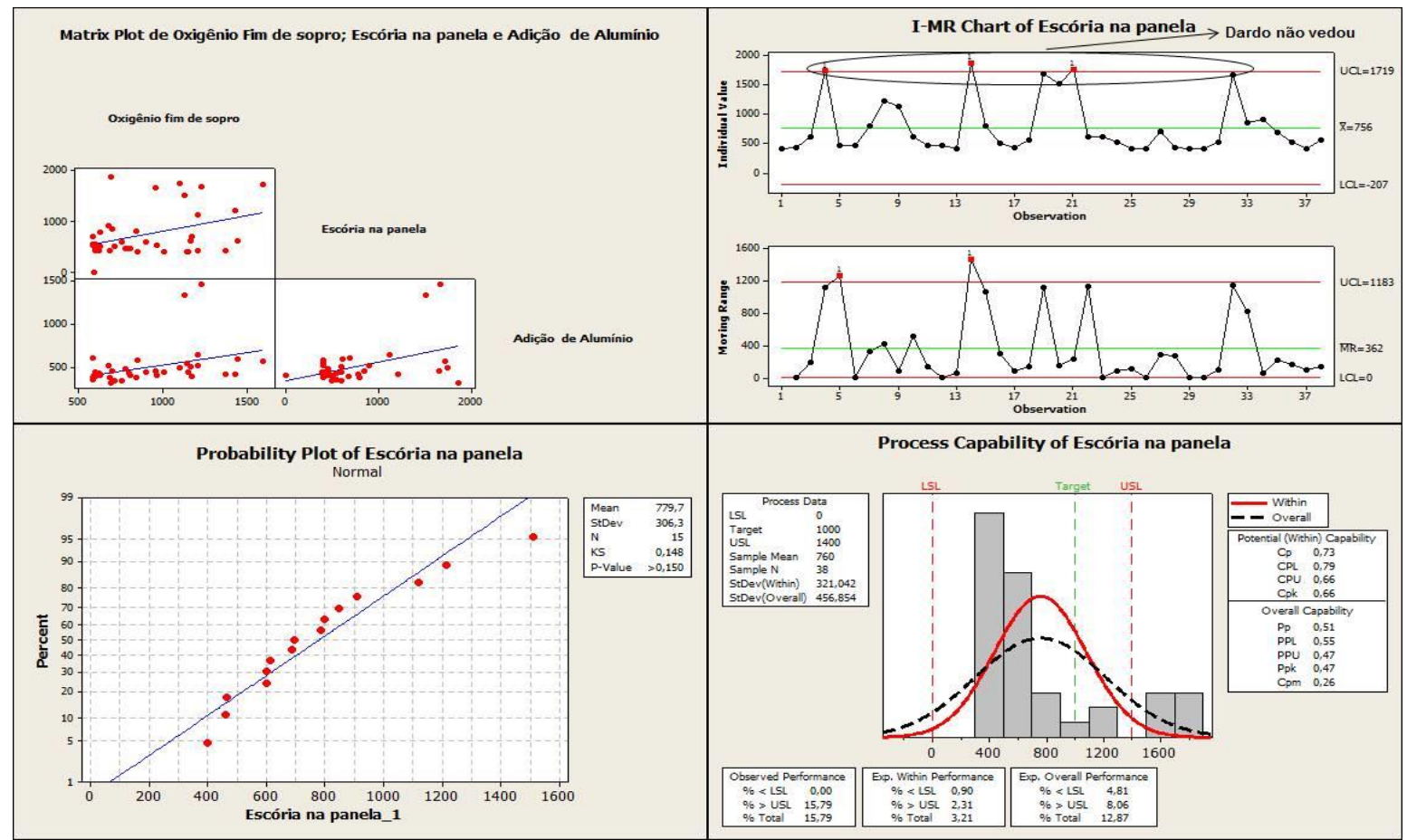

Figura 7- Correlação entre o oxigênio fim de sopro com a escória na panela e a adição de alumínio com a meta específica de redução da escória na panela $(1000 \mathrm{~kg})$

Uma outra fonte de geração de retorno de corridas devido a obstrução da válvula da panela é a escória na panela podendo reagir com a alumina formando aluminato de cálcio de difícil flotação [1].

A figura 8, apresenta a região do clogging, que é representada por uma seta, contêm $82,36 \%$ de alumina, onde precisa-se de temperaturas de lingotamento superiores a $1789^{\circ} \mathrm{C}$ para termos inclusões líquidas e não ocorrer o clogging. Percentuais de $\mathrm{CaO}$ entre 2 e $20 \%$ nas inclusões aumentam consideravelmente as chances de obstrução pois são sólidas na temperatura de lingotamento, sendo neste caso, tem-se um CaO de $17,64 \%$.
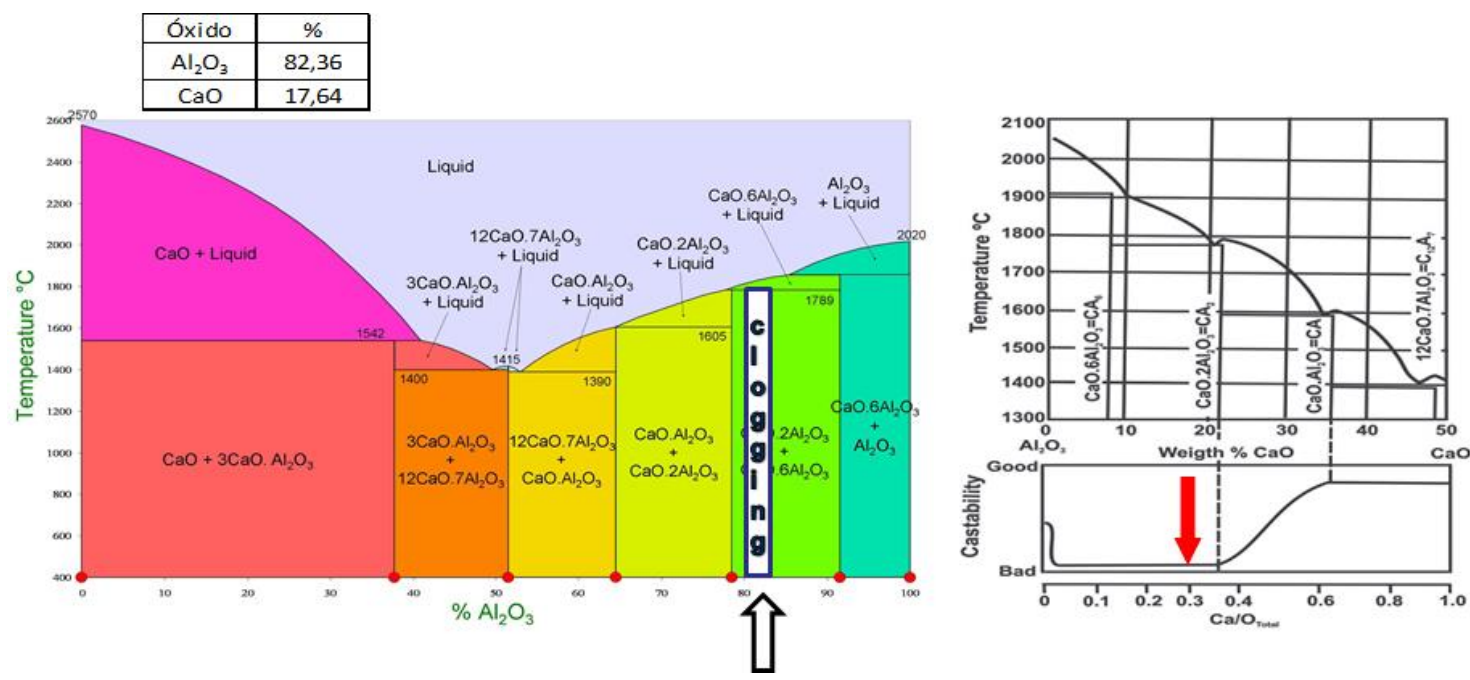

Figura 8- Região de formação do clogging apresentada em diagramas binários [1]

A figura 9, apresentam os ternários que representam aços do lingotamento contínuo de placas, onde mostraram os resultados das inclusões. No ternário cuja a rota de 
produção é o RH e Forno Panela, as corridas obtiveram bons tratamentos no refino e não ocorreram retornos de corrida por obstrução, porém, o ternário contendo a rota Estação de Borbulhamento apresentou clogging e obstruiu a panela retornando a corrida, ou seja, a corrida de rota Borbulhamento apresentou inclusões de aluminato de cálcio, enquanto as outras duas rotas, apresentaram inclusões de alumina [3]. Os aços destas corridas não são tratados com injeção de $\mathrm{CaSi}$, onde, o tratamento com CaSi, tem a função de modificação o ponto de fusão das inclusões, obtendo inclusões na região ótima para a não ocorrência de obstrução da válvula da panela.

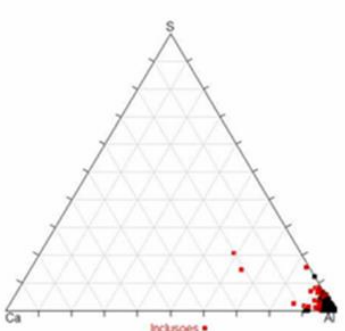

Rota: RH

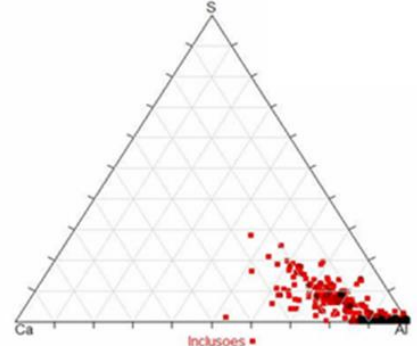

Rota: Borbulhamento

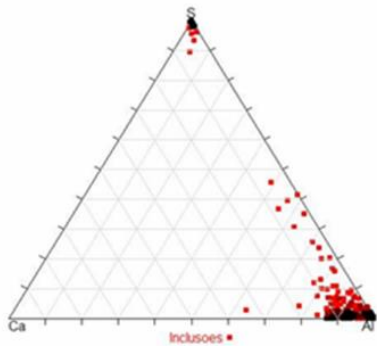

Rota: Forno Panela

Figura 9- Levantamento de dados dos Ternários de aços produzidos no Lingotamento Contínuo de Placas em três diferentes rotas de processo

A figura 10, apresentam os ternários para aços com injeção da CaSi para serem comparados com a figura 9 , com regiões com e sem clogging.

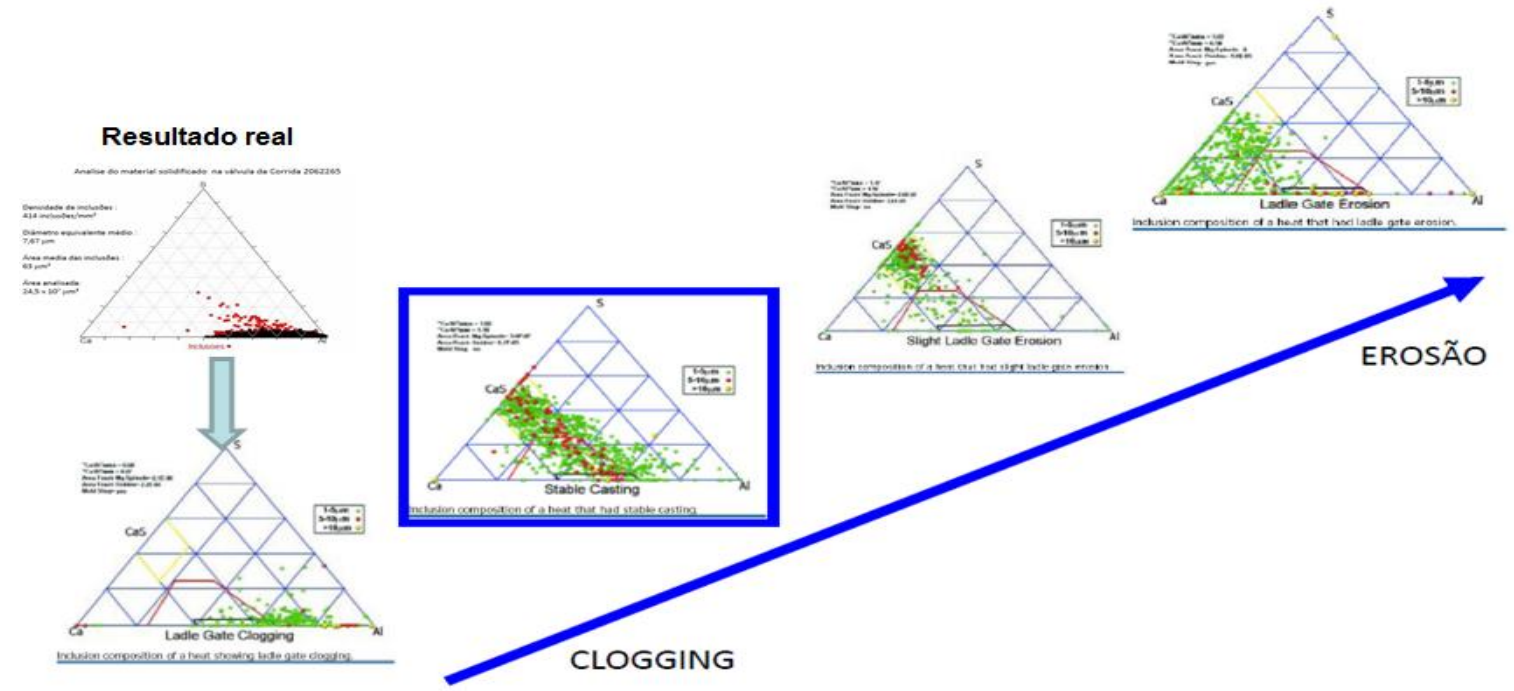

Figura 10- Evolução dos Ternários de aços com injeção de CaSi

\subsection{Problema Crítico: Peso de aço na baia antes da panela ir para a torre dos Lingotamentos Contínuos}

O apontamento da produção de aço líquido é realizado no momento em que se posiciona o aço na torre dos Lingotamentos Contínuos, e foi observado que em média, tinha-se uma diferença de quase 2,5 toneladas do aço líquido previsto com o real medido na torre do Lingotamento Contínuo. Foi realizada a análise do processo e a quantificação do relacionamento entre variáveis (potencial causa versus problema focado), sendo definidos os seguintes parâmetros de processo a serem avaliados: 
peso previsto x real da carga metálica do gusa e da sucata; borda Livre na panela para tratamento no refino secundário e controle de temperatura do aço.

A pesagem correta do gusa previsto na receita é primordial para que não ocorra variações de carga nos Convertedores e gerar o aço na baia antes da panela ir para a torre do Lingotamento, pois, se a pesagem real de gusa for acima do previsto, teremos que remover o excesso de aço da panela para ter "borda livre" suficiente para tratar no $\mathrm{RH}$ ou Forno Panela e desta forma, aumentar a perda de aço e muito das vezes, a ocorrência de quebra de sequência na máquina de lingotamento, uma vez que não teríamos tempo hábil para remover o aço em excesso na panela.

Com um acompanhamento de pesagem e carregamento de sucatas nos Convertedores, pôde-se verificar o impacto de trocas de receitas e utilização de canaletas reservas no resultado da carga metálica dos Convertedores.

A borda livre na panela para tratamento no refino secundário é um parâmetro correlacionável com o peso correto da carga metálica que é composta por sucata e gusa, ou seja, a receita prevista de sucata e de gusa é proporcional ao rendimento de aço líquido estimado na panela que por sua vez é proporcional à borda livre para ser tratada no refino secundário, conforme exposto anteriormente. Um outro fator que pode afetar a borda livre na panela são as variações de espessura de refratário durante a vida da panela. A figura 11 apresenta equação de regressão a borda livre de panelas novas (vida até 30 corridas) ficando em torno de $311 \mathrm{~mm}$; porém, $55 \%$ das vezes o resultado é inferior a $300 \mathrm{~mm}$ de borda livre. As medições mostram também que até 45 corridas de vida nas panelas corre-se o risco de não garantir a borda livre mínima para tratamento em todas as rotas no refino secundário. Esta situação certamente contribui para o envio das panelas nas baias da Aciaria.

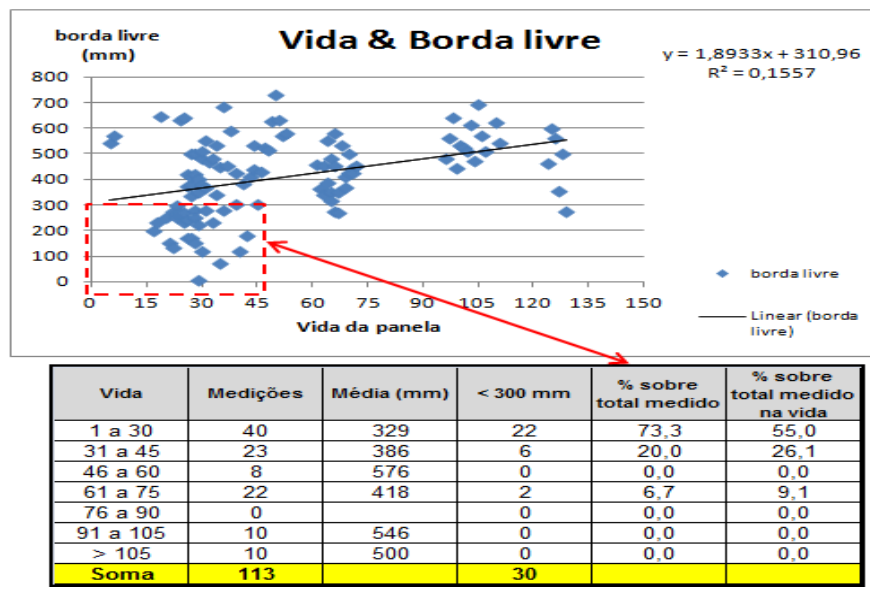

Figura 11- Vida de panela versus borda livre da panela

Em função das enormes variáveis do processo, é fundamental que se tenha um modelo de temperatura que consiga correlacionar todos as variáveis do processo, aumentando a robustez do processo de modo a não termos perda térmica do aço no processo e para isto, um modelo de temperatura da Aciaria é fundamental para o processo. 


\subsection{Execução do plano de ação}

\subsubsection{Plano de ação do problema crítico: Obstrução da válvula da panela no Lingotamento Contínuo de Placas (LCP):}

Reduzir o oxigênio fim de sopro: foi padronizado a utilização de um balanço de sucata em função da temperatura do Gusa. A figura 12 apresenta o resultado de oxigênio fim de sopro, com o resultado médio de 850 ppm, menor que 900 ppm cuja especificação é recomendada para qualidade dos aços e desta forma evitando o retorno de corrida por obstrução da panela. A partir de janeiro 2016 a agosto 2017, este resulta médio atingiu a marca de $740 \mathrm{ppm}$.

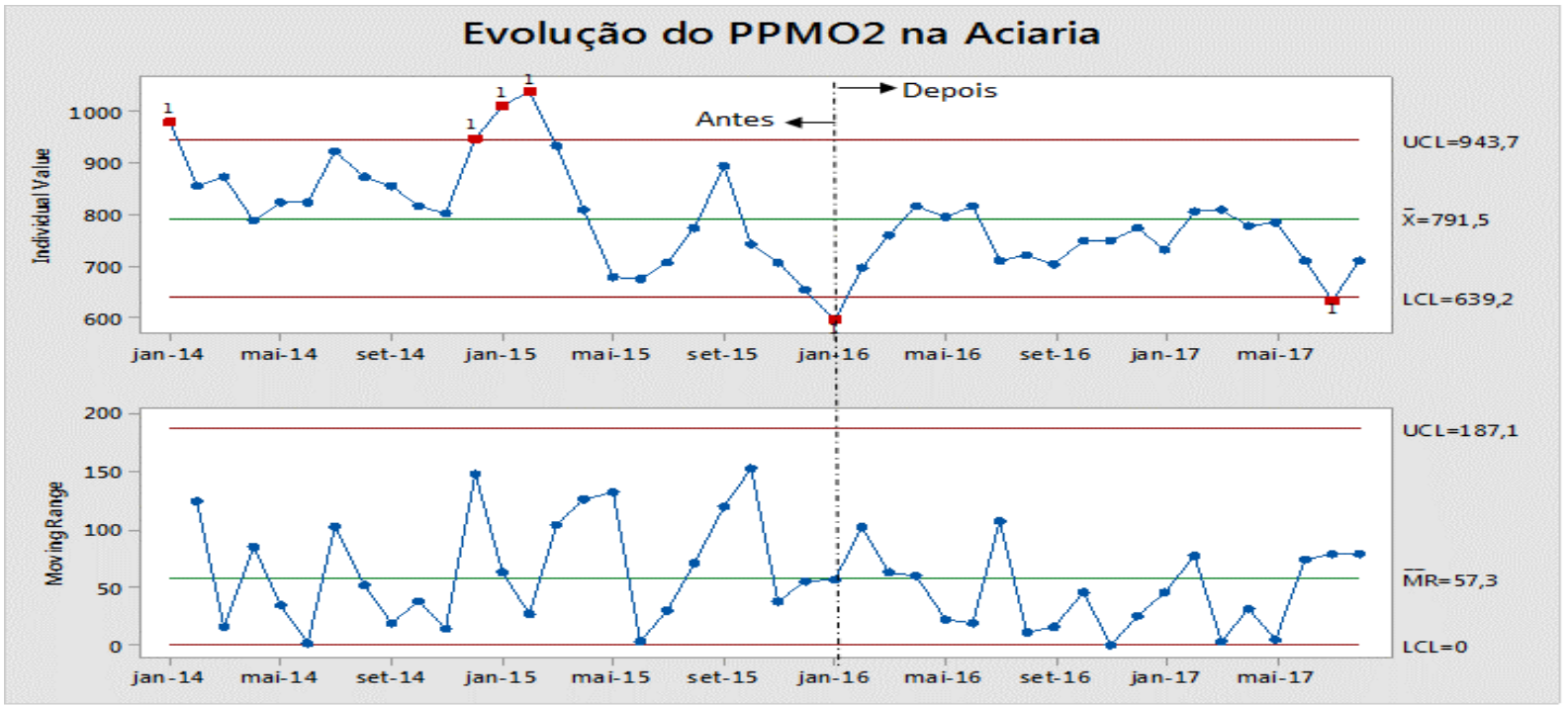

Figura 12- Evolução do ppm de oxigênio na Aciaria

Escória na panela: foi criado um item de verificação para o operador em utilizar $100 \%$ do dardo controlando sua utilização e índice de acerto durante o vazamento do aço nos Convertedores, visto na tabela 2.

Tabela 2- Criação do item de verificação da utilização do dardo na Aciaria

\begin{tabular}{|c|c|c|c|c|}
\hline G GERDAU & \multicolumn{4}{|c|}{ PROCEDIMENTO DE ATUALIZAÇÄO E TRATATIVA DE DESVIOS GESTÄO Ả VISTA } \\
\hline & \multicolumn{4}{|c|}{ TRATATIVA DE DESVIOS/OCORRÊNCIAS } \\
\hline iv & $\begin{array}{l}\text { Especificaçäo } \\
\text { (resultado verde) }\end{array}$ & $\begin{array}{l}\text { Resultado Indesejado } \\
\text { (resultado vermelho) }\end{array}$ & Ação Imediata & Quando Medir \\
\hline Utilizą̧ão do Dardo & $\operatorname{sim}$ (utilizou) & Não (ñ̃o utilizou) & $\begin{array}{l}\text { Acionar a equipe de manutenção da MRE (se fora do horário administrativo } \\
\text { acionar José Ricardo de Almeida: } 2222.5096 \text { lou programar reparo ou troca } \\
\text { do furo para atender o tempo minimo de } 4,5 \mathrm{~min} \text {. }\end{array}$ & Toda corrida \\
\hline Acerto do dardo & $\operatorname{sim}$ (acertou) & Não (errou) & Limpar boca ou acionar a equipe da Magnesita para ajuste de coordenadas. & Toda corrida \\
\hline Tempo de vazamento & 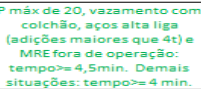 & 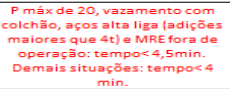 & Programar troca ou reparo do furo de corrida. & \\
\hline
\end{tabular}

Escória na panela podendo reagir com a alumina formando aluminato de cálcio de difícil flotação: foi inserido no padrão dos aços peritético e médio carbono com o grau de desoxidação acalmado ao alumínio e silício para injetar $\mathrm{CaSi}$ e os aços Baixo Carbono com grau de desoxidação acalmado ao alumínio, foi alterado a estratégia de refino secundário de Borbulhamento para $\mathrm{RH}$, conforme visto na figura 13. 
Estratéaia reducão do cloaqing sem injeção de CaSi utilizando a rota $\mathrm{RH}$ :
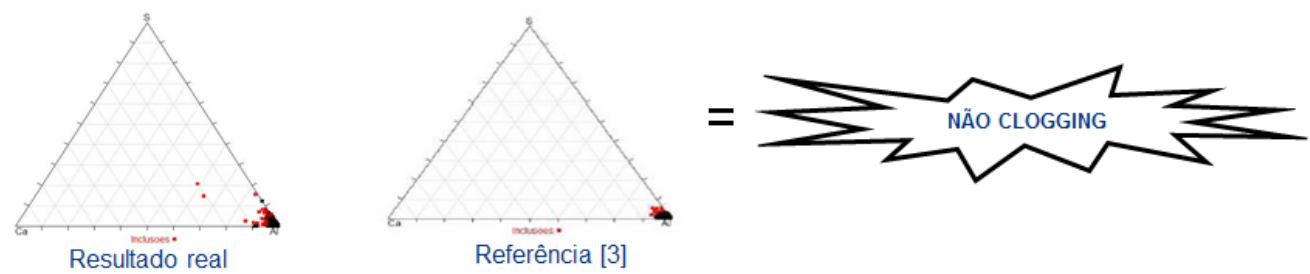

Estratégia redução do clogging com injeção de CaSi:
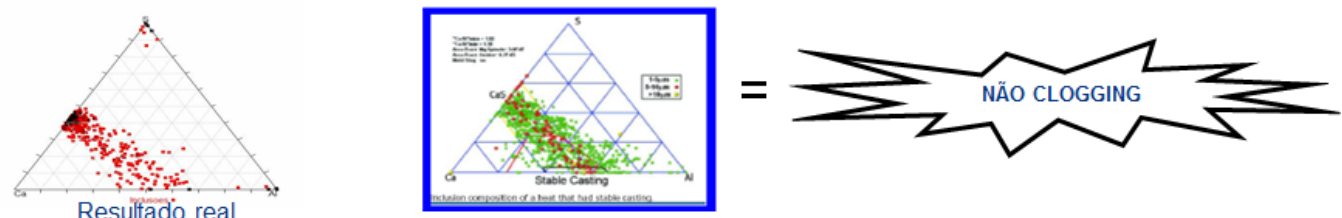

Figura 13- Mudança de estratégica de produção na rota do Lingotamento Contínuo de placas

\subsubsection{Plano de ação do problema crítico: Peso de aço na baia antes da panela ir para a torre dos Lingotamentos Contínuos:}

Peso previsto $x$ real da carga metálica do gusa e da sucata: foi criado dois itens de verificação, um para a sucata e outro para o gusa, onde os índices de acertos para sucatas é de (90\%) com histórico (Junho 2014) de (52\%) e gusa de (75\%) com histórico (Junho 2014) de (48\%), conforme visto na figura 14.

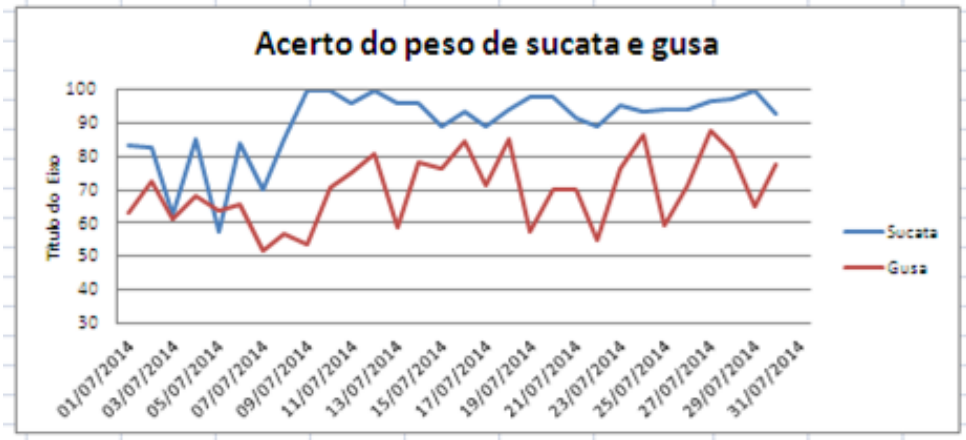

Figura 14- Criação do item de verificação de peso previsto e real de sucata e gusa

Borda livre na panela para tratamento no refino secundário: foi criado novos limites de borda livre atendendo à vida de panela de aço, conforme visto na tabela 3.

Tabela 3- Novos limites de borda livre na panela de aço

\begin{tabular}{|l|c|c|}
\hline $\begin{array}{l}\text { Limites para liberação das corridas } \\
\text { para tra tamento por rota }\end{array}$ & $\begin{array}{c}\text { Borda Mínima } \\
(\mathbf{m m})\end{array}$ & $\begin{array}{c}\text { Borda Máxima } \\
(\mathbf{m m})\end{array}$ \\
\hline RH's & 250 & 700 \\
\hline Rota dupla RH e FP & 250 & 700 \\
\hline Formo Panela & 200 & 900 \\
\hline Forno Panela p/ Borbulhar & 150 & 900 \\
\hline Estação de Borbulhamento & 150 & - \\
\hline
\end{tabular}

Controle de temperatura do aço: foi criado o modelo de temperatura da Aciaria que faz também a coordenação alertando o operador dos limites de trânsito e quando está fora do padrão. 


\subsection{Verificação dos Resultados}

Os Resultados de performance para atendimento à perda metálica superaram a meta inicialmente definida de $32 \%$, sendo obtida uma redução de 50,8\%, figura 15 .

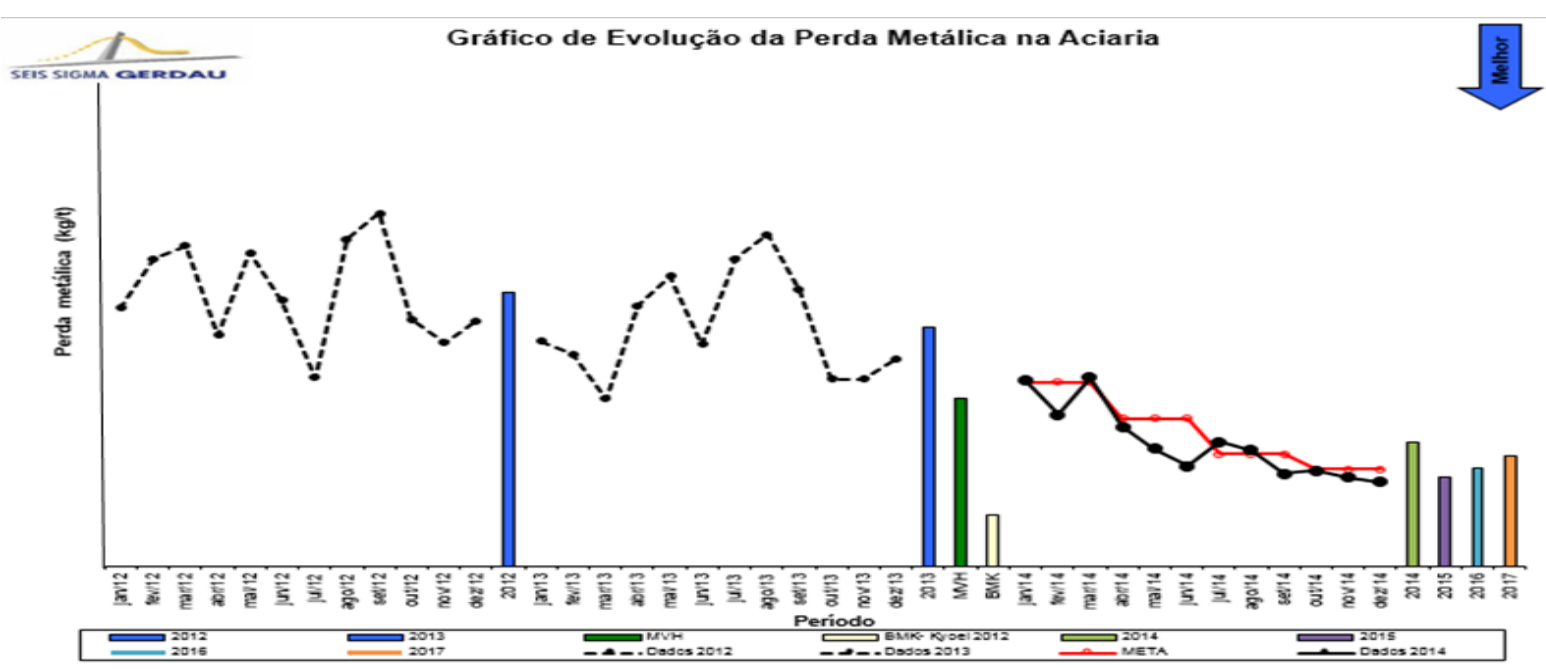

Figura 15- Resultado de performance e atendimento ao indicador de perda metálica

\section{CONCLUSÃo}

O estudo realizado mostrou que o balanço de massa da Aciaria foi fundamental para identificação dos pontos de perdas e pontapé inicial de todo o trabalho, onde informações confiáveis nos levam a tomadas de decisões assertivas. As perdas nos processos foram por: perda no Distribuidor $(24,7 \%)$, perda por corte de sequência $(17,5 \%)$, retorno de corrida por baixa temperatura do aço na panela (16,3\%); perda por obstrução da panela no Lingotamento de Placas $(8,8 \%)$, onde são correlacionáveis, onde foram tratados como priorização as perdas por obstrução na válvula da panela no Lingotamento Contínuo de Placas e aço na baia antes de ir para a torre do lingotamento.

Houve uma grande mudança no processo, principalmente na estratégia de tratamento dos aços na rota do Lingotamento Continuo de placas, onde os aços peritéticos e médio carbono com o grau de desoxidação acalmado ao alumínio e silício injeta-se CaSi e os aços Baixo Carbono com grau de desoxidação acalmado ao alumínio, foi alterado a estratégia de refino secundário de Borbulhamento para $\mathrm{RH}$.

A realização das ações, reduziu a perda metálica em 50,8 \% em relação ao valor histórico. $\mathrm{O}$ grande desafio deste projeto além de sua meta, foi buscar a interação entre as equipes de todos os processos da Aciaria (do gusa até o produto lingotado), TI, TA e Gerência de Produtos; fato este superado em função do grande comprometimento e competência de toda a equipe.

\section{REFERÊNCIAS}

1 Bannenberg N. Inclusion modification to prevent nozzle clogging. In: Steelmaking Conference Proceedings. 1995. p. 457-463.

2 Relatório da Missão na Gerdau da Empresa Nippon Steel \& Sumitomo Metal Corporation- Kashima (2012).

3 Story SR,Fruehan RJ, Piccone TJ, Potter M. Inclusion analysis to predict casting behavior. Iron and steel technology. 2004;1(9):163-169. 